\title{
Association between polymorphisms in RMII, TOP3A, and BLM and risk of cancer, a case-control study
} Karin Broberg*1, Elizabeth Huynh ${ }^{1}$, Karin Schläwicke Engström¹, Jonas Björk ${ }^{2}$, Maria Albin ${ }^{1}$, Christian Ingvar ${ }^{3}$, Håkan Olsson ${ }^{\dagger 4}$ and Mattias Höglund ${ }^{\dagger 5}$

Address: ${ }^{1}$ Department of Occupational and Environmental Medicine, Lund University, Lund, Sweden, ${ }^{2}$ Competence Centre for Clinical Research, Lund University Hospital, Lund, Sweden, ${ }^{3}$ Department of Surgery, Lund University, Lund, Sweden, ${ }^{4}$ Department of Oncology, Lund University, Lund, Sweden and ${ }^{5}$ Department of Clinical Genetics/SCIBLU Genomics, DNA Microarray Resource Centre Lund University, Lund, Sweden

Email: Karin Broberg* - karin.broberg@med.lu.se; Elizabeth Huynh - liseo_82@hotmail.com;

Karin Schläwicke Engström - karin.engstrom@med.lu.se; Jonas Björk - jonas.bjork@skane.se; Maria Albin - maria.albin@med.lu.se;

Christian Ingvar - christian.ingvar@med.lu.se; Håkan Olsson - hakan.olsson@med.lu.se; Mattias Höglund - mattias.hoglund@med.lu.se

* Corresponding author †Equal contributors

Published: II May 2009

BMC Cancer 2009, 9:140 doi:10.1186/147I-2407-9-140

This article is available from: http://www.biomedcentral.com/I47/-2407/9//40

(c) 2009 Broberg et al; licensee BioMed Central Ltd.

This is an Open Access article distributed under the terms of the Creative Commons Attribution License (http://creativecommons.org/licenses/by/2.0), which permits unrestricted use, distribution, and reproduction in any medium, provided the original work is properly cited.

\begin{abstract}
Background: Mutations altering BLM function are associated with highly elevated cancer susceptibility (Bloom syndrome). Thus, genetic variants of BLM and proteins that form complexes with BLM, such as TOP3A and RMII, might affect cancer risk as well.

Methods: In this study we have studied 26 tagged single nucleotide polymorphisms (tagSNPs) in $R M I I$, TOP3A, and BLM and their associations with cancer risk in acute myeloid leukemia/ myelodysplatic syndromes (AML/MDS; $N=152)$, malignant melanoma $(N=170)$, and bladder cancer $(N=61)$. Two population-based control groups were used $(N=119$ and $N=156)$.

Results: Based on consistency in effect estimates for the three cancer forms and similar allelic frequencies of the variant alleles in the control groups, two SNPs in TOP3A (rs/563634 and rs I 2945597) and two SNPs in BLM (rs40I549 and rs2532 105) were selected for analysis in breast cancer cases $(N=200)$ and a control group recruited from spouses of cancer patients $(N=|3|)$. The rs 12945597 in TOP3A and rs2532 105 in BLM showed increased risk for breast cancer. We then combined all cases $(N=584)$ and controls $(N=406)$ respectively and found significantly increased risk for variant carriers of $\mathrm{rs} 1563634 \mathrm{~A} / \mathrm{G}$ (AG carriers $\mathrm{OR}=1.7[95 \% \mathrm{Cl}$ I.I-2.6], AA carriers OR $=1.8[1.2-2.8]), r s$ I $2945597 \mathrm{G} / \mathrm{A}$ (GA carriers OR = I.5 [I. I-I.9], AA carriers OR = I.6 [I.0-2.5]), and $\mathrm{rs} 2532105 \mathrm{C} / \mathrm{T}(\mathrm{CT}+\mathrm{TT}$ carriers $\mathrm{OR}=1.8$ [I.4-2.5]). Gene-gene interaction analysis suggested an additive effect of carrying more than one risk allele. For the variants of TOP3A, the risk increment was more pronounced for older carriers.
\end{abstract}

Conclusion: These results further support a role of low-penetrance genes involved in BLMassociated homologous recombination for cancer risk. 


\section{Background}

Bloom syndrome is a condition characterised by growth inhibition, light sensitivity, and high incidence of cancer in early life [1]. Although there appears to be a predominance of lymphocytic leukemia and lymphoma, many cancer types are seen in this condition. A defining feature of Bloom's syndrome is an elevated frequency of sister chromatide exchanges. These arise from crossing over of chromatide arms during homologous recombination, a ubiquitous process that exists to repair DNA doublestranded breaks and damaged replication forks. Whereas crossing over is required in meiosis, it can in mitotic cells be associated with a detrimental loss of heterozygosity, a common feature in neoplastic cells.

BLM, the helicase mutated in Bloom syndrome, is found in protein complexes together with topoisomerase IIIa (TOP3A) and a newly identified member, the RECQmediated genome instabilitity 1 (RMI1) protein, that process double Holliday junction intermediates into noncrossover recombinants [2-5]. This dissolution activity of the BLM-TOP3A-RMI1 complex is thought to be critical for the suppression of DNA crossover formation in mitotic cells and cancer avoidance in humans. The complex might process many other DNA structures as well, such as stalled replication forks [6] and has been implicated in checkpoint signalling and checkpoint responses during DNA damage [5].

Since mutations that alter BLM function are associated with elevated cancer susceptibility, we reasoned that genetic variants of $B L M$ and other proteins that form a complex with BLM might affect the risk for different cancer forms. In order to test this hypothesis we analysed in this study polymorphisms in the RMI1, TOP3A and BLM, and their association with cancer risk in available casecontrol materials, namely AML/MDSs (acute myeloid leukemia and myelodysplastic syndromes), malignant melanoma, and bladder and breast cancer.

\section{Methods \\ Study populations}

The studies have been approved by the Ethics Committee of Lund University. All study participants gave informed consent before participation in the study. We did not ask for ethnicity of the study participants. However, based on their names, the absolute majority of the participants was of European descent (predominating Swedish). All cancer patients were voluntarily recruited from the Southern Health Care Region of Sweden. Study population characteristics for different cancer forms are shown in Table 1. The AML/MDS and the malignant melanoma study populations are described in more detail in Broberg et al. [7]. In short, the diagnoses were: 78 cases of AMLand, 56 cases of MDS, and in 18 subjects AML preceeded by a MDS. All the participating melanoma patients $(\mathrm{N}=170)$ had a primary cutaneous melanoma diagnosed except for two patients, who presented with metastatic disease without known primary site of their melanoma. The AML/MDS patients' samples were collected during the years 1998-2004 and the malignant melanoma samples during 2001-2005. The control group was drawn randomly from the Regional Population Registry during 2001-2004, frequency matched with the cases series with respect to sex, year of birth, as well as country of living. The bladder study groups have been studied earlier and are described more in detail in Broberg et al. [8]. The bladder cancer patients' $(\mathrm{N}=61)$ and the control individuals' samples $(\mathrm{N}=156)$ (mouth washes) were collected during 1995-2000. The control group was drawn randomly from the Regional Population Registry during 1995-2000, frequency matched with the cases with respect to sex, year of birth, as well as country of living. The breast cancer patients all came for treatment at the Oncology Clinic at Lund University Hospital between 1990 and 1998, where they accepted to participate in the study and donated blood samples. The case group encompassed 200 patients, all of which were women. According to the TNM classification, 6 individuals were in stage 0,79 in stage I, 72 in stage II and 15 in stage III. Twenty-eight cases could not be classified, mainly because of no axillary sampling performed due to locally advanced tumors. The control group consisted of 131 accompanying female spouses to cancer

Table I: Study characteristics of cases and controls for the different cancer forms.

\begin{tabular}{llllllll}
\hline & AML/MDSa & Malignant melanoma & & \multicolumn{2}{l}{ Bladder cancer } & & Breast cancer \\
& Cases & Cases & Controls & Cases & Controls & Cases & Controls \\
\hline $\mathrm{N}$ & 152 & 170 & 119 & 61 & 156 & 200 & 131 \\
Median age (range) & 72 & 66 & 68 & 69 & 69 & 59 & 63 \\
& $(22-95)$ & $(24-80)$ & $(22-96)$ & $(35-85)$ & $(21-90)$ & $(34-86)$ & $(23-85)$ \\
Women/Men & $73 / 79$ & $87 / 83$ & $53 / 66$ & $9 / 52$ & $34 / 122$ & $200 / 0$ & $131 / 0$ \\
$(\%)$ & $(48 / 52)$ & $(51 / 49)$ & $(44.5 / 55.5)$ & $(15 / 85)$ & $(22 / 78)$ & $(100 / 0)$ & $(100 / 0)$ \\
\hline
\end{tabular}

a AML/MDS denotes acute myeloid leukemia/myelodysplastic syndromes 
patients coming to the Oncology Clinic for treatment, recruited from Southern Sweden. The control individuals filled in a questionnaire about their health status and donated a blood sample. Spouses without former cancer were selected for the study.

\section{Polymorphism selection and initial screening}

Polymorphisms were selected in Bloom syndrome related genes (RMI1, TOP3A and BLM) from the HapMap data http://www.hapmap.org. TagSNPs were identified from the CEU population data (CEPH, Utah residents with ancestry from northern and western Europe), and by running the data in Haploview ([9]). The TagSNPs chosen showed an allelic frequency of at least $10 \%$. DNA extractions for all samples were made with QIAmp 96 DNA blood kit (Qiagen, Hilden, Germany) by SWEGENE resource centre for Profiling Polygenic Diseases in Malmö University hospital, Sweden, apart from the blood samples from the breast control group, which were extracted for DNA with Wizard Genomic DNA Purification Kit (Promega, Madison, WI, USA). The polymorphisms were analyzed with matrix-assisted laser desorption/ionization time-of-flight

(MALDI-TOF) mass spectrometry Sequenom $^{\mathrm{TM}}$, San Diego, CA) at the SWEGENE resource centre for Profiling Polygenic Diseases in Malmö University hospital. For the Sequenom assays, 20 percent of the samples were rerun and negative controls (water instead of DNA) were included in each run. Out of 28 tagSNPs analysed, 2 failed in the analysis, which left us with 26 tagSNPs. The frequency of individuals with missing genotype data ranged between $1.3 \%-6.8 \% / S N P$ assay for leukaemia and malignant melanoma, and 7.7\%-12.7\%/SNP assay for bladder cancer. The drop rate for bladder cancer probably reflects that there was limited amount of DNA left. We carefully evaluated the results of each assay and only included those samples that demonstrated positive signals in most assays. Selection of tagSNPs for further analysis of the breast cancer study population was based on changes in effect estimates (computed as odds ratios, ORs) in the same direction (reduced or increased risk) in at least two cancer forms of the three analyzed. Secondly, the allele frequencies in the two control groups should be similar.

\section{Genotyping of polymorphisms in the breast cancer/control material}

The genotyping was performed on 200 cases of breast cancer and 131 controls. The selected polymorphisms were rs1563634 and rs12945597 (C_31923586_10) in TOP3A, rs401549 and rs2532105 in BLM. Taqman assays and allelic discrimination was run on an ABI PRISM 7000 (Applied Biosystems). The Taqman assay reaction volume was $25 \mu$ l containing: $1 \times$ Universal Taqman mix (Applied Biosystems), each primer at $0.45 \mu \mathrm{M}$ mixed with each probe at $0.10 \mu \mathrm{M}$, and 5-12 ng of DNA template. The thermal cycle protocol was $95^{\circ} \mathrm{C}$ for $10 \mathrm{~min}, 95^{\circ} \mathrm{C}$ for 15 sec and $60^{\circ} \mathrm{C}$ for $1 \mathrm{~min}$ (40 cycles). Plate reading for allelic discrimination was performed under $60^{\circ} \mathrm{C}$ for 1 min. For all assays, at least $5 \%$ of the samples were reanalyzed and the concordance rate of these analyses was $100 \%$.

\section{Statistical analysis}

The Hardy-Weinberg equilibrium (HWE) test was undertaken using the chi-square test in the control groups. Effect estimates were computed as odds ratios (ORs) with $95 \%$ confidence intervals (95\% CIs) by logistic regression using SPSS 14.0 (version 14; SPSS, Chicago, IL, USA). For rs 1563634 in TOP3A, the reference category was changed in Tables 2, 3, 4 and 5 to the variant homozygous genotype in order to display cancer risk increment. The analyses were performed both without any adjustments, as well as with adjustments for sex and age. When stratifying for age, subjects were categorized into two groups, based on the median age among the cancer cases and control groups combined as a cut-off ( $<65$ and $\geq 65$ years). The stratified analysis was adjusted for sex.

To assess false positives, the False Positive Report Probability (FPRP) [10] was calculated, based on observed association data, according to the formula; $\alpha^{*}(1-\pi) /\left(\alpha^{*}(1-\pi)\right.$ $\left.+(1-\beta)^{*} \pi\right), \alpha$ denotes the $\mathrm{p}$-values from the logistic regression analyses, 1- $\beta$ denotes the statistical power for the tests and $\pi$ denotes the prior probability of a true association of the tested genetic variant and outcome. OR values above 1.5 were considered as this is a likely threshold value for important biologic effects $[11,12]$. The prior probability employed was set to 0.01 (low probability) and 0.1 (high probability) for all SNPs. The FPRP treshold was set to 0.5 , thus statistically significant SNPs with a FPRP above 0.5 were in this study not considered reliable to classify as true positives. These values, as well as the values for ORs and 95\% CIs were entered into the online spreadsheet included in Wacholder et al. [10] for FPRP calculations.

\section{Bioinformatics}

SNPs with a statistically significant association were further evaluated in silico for potential function. PupaSNP (http://www.pupasnp.org, [13,14]) was employed in order to detect SNPs potentially affecting transcription factor binding sites, exonic splicing enhancers/silencers, triplexes, splice sites and microRNA target sites. Emboss CpGPlot http://www.ebi.ac.uk/emboss/cpgplot/ was employed to detect CpG-rich areas.

\section{Results}

All SNPs were in HWE in the control groups for AML/ MDS, malignant melanoma, and bladder cancer. The four 
Table 2: Associations of polymorphisms in A) TOP3A and B) BLM and cancer risk (presented as odds ratios and $95 \%$ confidence interval) in different cancer forms. ${ }^{a}$

\begin{tabular}{|c|c|c|c|c|c|c|c|}
\hline Cancer type & Polymorphism & $\begin{array}{l}\text { Risk allele \% } \\
\text { Cases/controls }\end{array}$ & Genotype & Cases & Controls & OR & $95 \% \mathrm{Cl}$ \\
\hline \multirow[t]{3}{*}{ AML/MDS } & $\begin{array}{l}\text { TOP3A } \\
\text { rsI563634b }\end{array}$ & $75 / 66$ & AA & 11 & 14 & $1.0 c, d$ & - \\
\hline & & & AG & 54 & 52 & 1.3 & $0.53-3.1$ \\
\hline & & & GG & 84 & 52 & 2.0 & $0.82-4.7$ \\
\hline \multirow{3}{*}{$\begin{array}{l}\text { Malignant } \\
\text { melanoma }\end{array}$} & & $75 / 66$ & $A A$ & 12 & 14 & 1.0 & - \\
\hline & & & AG & 60 & 52 & 1.4 & $0.58-3.2$ \\
\hline & & & GG & 96 & 52 & 2.2 & $0.93-5.1$ \\
\hline Bladder & & $68 / 67$ & $A A$ & 3 & 19 & 1.0 & - \\
\hline \multirow[t]{2}{*}{ cancer } & & & AG & 32 & 54 & 3.9 & $1.1-14$ \\
\hline & & & GG & 25 & 66 & 2.5 & $0.67-9.1$ \\
\hline \multirow[t]{3}{*}{ Breast cancer } & & $68 / 68$ & $A A$ & 19 & 16 & 1.0 & - \\
\hline & & & AG & 88 & 48 & 1.5 & $0.72-3.2$ \\
\hline & & & GG & 92 & 66 & 1.2 & $0.57-2.5$ \\
\hline \multirow[t]{3}{*}{ AML/MDS } & $\begin{array}{l}\text { TOP3A } \\
\text { rsI } 2945597\end{array}$ & $37 / 25$ & GG & 61 & 64 & 1.0 & - \\
\hline & & & GA & 63 & 49 & 1.3 & $0.76-2.2$ \\
\hline & & & $A A$ & 22 & 5 & 4.9 & I.7-I4 \\
\hline \multirow{3}{*}{$\begin{array}{l}\text { Malignant } \\
\text { melanoma }\end{array}$} & & $32 / 25$ & GG & 78 & 64 & 1.0 & - \\
\hline & & & GA & 72 & 49 & 1.2 & $0.74-2.0$ \\
\hline & & & $A A$ & 18 & 5 & 3.0 & $1.0-8.4$ \\
\hline Bladder & & $36 / 30$ & GG & 26 & 73 & 1.0 & - \\
\hline \multirow[t]{2}{*}{ cancer } & & & GA & 25 & 49 & 1.4 & $0.75-2.8$ \\
\hline & & & $A A$ & 9 & 17 & 1.5 & $0.58-3.7$ \\
\hline \multirow[t]{3}{*}{ Breast cancer } & & $31 / 26$ & GG & 96 & 76 & 1.0 & - \\
\hline & & & GA & 84 & 40 & 1.7 & $1.0-2.7$ \\
\hline & & & $A A$ & 20 & 15 & I.I & $0.52-2.3$ \\
\hline \multirow[t]{3}{*}{ AML/MDS } & $\begin{array}{l}\text { BLM } \\
\text { rs40I549 }\end{array}$ & $31 / 30$ & AA & 65 & 57 & 1.0 & - \\
\hline & & & $A G$ & 75 & 51 & 1.3 & $0.77-2.1$ \\
\hline & & & GG & 9 & 10 & 0.77 & $0.29-2.0$ \\
\hline \multirow{3}{*}{$\begin{array}{l}\text { Malignant } \\
\text { melanoma }\end{array}$} & & $36 / 30$ & $A A$ & 62 & 57 & 1.0 & - \\
\hline & & & AG & 90 & 51 & 1.6 & $0.98-2.7$ \\
\hline & & & GG & 16 & 10 & 1.5 & $0.6 I-3.5$ \\
\hline Bladder & & $37 / 30$ & $A A$ & 26 & 64 & 1.0 & - \\
\hline \multirow[t]{2}{*}{ cancer } & & & AG & 24 & 67 & 0.90 & $0.47-1.7$ \\
\hline & & & GG & 10 & 8 & 3.1 & $1.1-8.7$ \\
\hline \multirow[t]{3}{*}{ Breast cancer } & & $34 / 33$ & $A A$ & 87 & 58 & 1.0 & - \\
\hline & & & AG & 94 & 61 & 1.0 & $0.65-1.6$ \\
\hline & & & GG & 19 & 12 & 1.1 & $0.48-2.4$ \\
\hline \multirow[t]{2}{*}{ AML/MDS } & $\begin{array}{l}\text { BLM } \\
\text { rs2532।05 }\end{array}$ & $16 / 12$ & $\mathrm{CC}$ & 103 & 90 & 1.0 & - \\
\hline & & & $\mathrm{CT}+\mathrm{TT}$ e & 46 & 27 & 1.4 & $0.83-2.5$ \\
\hline \multirow{2}{*}{$\begin{array}{l}\text { Malignant } \\
\text { melanoma }\end{array}$} & & $18 / 12$ & $\mathrm{CC}$ & 109 & 90 & 1.0 & - \\
\hline & & & $\mathrm{CT}+\mathrm{TT}$ & 59 & 27 & 1.8 & $1.1-3.2$ \\
\hline \multirow[t]{2}{*}{ Bladder cancer } & & $20 / 10$ & $\mathrm{CC}$ & 40 & 111 & 1.0 & - \\
\hline & & & $\mathrm{CT}+\mathrm{TT}$ & 20 & 28 & 2.1 & $1.0-4.2$ \\
\hline \multirow[t]{2}{*}{ Breast cancer } & & $17 / 13$ & $\mathrm{CC}$ & 133 & 104 & 1.0 & - \\
\hline & & & $\mathrm{CT}+\mathrm{TT}$ & 67 & 27 & 2.0 & $1.2-3.3$ \\
\hline
\end{tabular}

a Observe that the control group for AML/MDS (acute myeloid leukemia/myelodsyplastic syndromes) and malignant melanoma case groups was the same. Logistic regression, adjusted for age and sex. Statistically significant associations $(p \leq 0.05)$ are denoted in bold.

bAccession number for polymorphisms in the SNP database of National Centre of Biotechnology Information, http://www.ncbi.nlm.nih.gov/sites/ entrez? db=snp

c Reference category.

d For rs 1563634, the reference category was changed to the variant allele in order to display cancer risk increment, and the risk allele frequency denotes thus the more common allele.

e Due to low variant allelic frequencies, the variant genotypes were merged. 
Table 3: Cancer risk estimates for gene-gene combinations of $A$ ) rs 12945597 (TOP3A) and rs2532 I05 (BLM) and B) rs I 563634 (TOP3A) and rs2532105 (BLM) in different cancer forms. ${ }^{a}$

\begin{tabular}{|c|c|c|c|}
\hline \multicolumn{4}{|l|}{ IIIA. rsI2945597+rs2532105 } \\
\hline & Genotype & OR & $95 \% \mathrm{Cl}$ \\
\hline \multirow[t]{4}{*}{ AML/MDS } & $\mathrm{GG}+\mathrm{CC}$ & 1.0 & - \\
\hline & GG+T- & 1.4 & $0.6 I-3.0$ \\
\hline & $A-+C C$ & 1.6 & $0.89-2.8$ \\
\hline & $\mathrm{A}-+\mathrm{T}-$ & 2.4 & I.I-5.4 \\
\hline \multirow[t]{4}{*}{ Malignant melanoma } & $\mathrm{GG}+\mathrm{CC}$ & 1.0 & - \\
\hline & $A-+C C$ & 1.7 & $0.98-3.0$ \\
\hline & GG+T- & 2.5 & $1.2-5.2$ \\
\hline & A-+T- & 2.4 & I.I-5.4 \\
\hline \multirow[t]{4}{*}{ Bladder cancer } & $\mathrm{GG}+\mathrm{CC}$ & 1.0 & - \\
\hline & $A-+C C$ & 1.4 & $0.68-2.9$ \\
\hline & GG+T- & 2.1 & $0.74-6.1$ \\
\hline & A-+T- & 3.0 & I.I-7.7 \\
\hline \multirow[t]{4}{*}{ Breast cancer } & $\mathrm{GG}+\mathrm{CC}$ & 1.0 & - \\
\hline & $A-+C C$ & 1.5 & $0.92-2.6$ \\
\hline & GG+T- & 2.0 & $1.0-4.1$ \\
\hline & $\mathrm{A}-+\mathrm{T}-$ & 3.0 & I.4-6.4 \\
\hline
\end{tabular}

IIIB. $r s 1563634^{b}+r s 2532105$

\begin{tabular}{llll}
\hline & Genotype & OR & $95 \% \mathrm{Cl}$ \\
\hline \multirow{2}{*}{ AML/MDS } & AA+CC & 1.0 & - \\
& AA+T- & 0.48 & $0.087-2.7$ \\
& G-+CC & 1.1 & $0.39-3.1$ \\
Malignant melanoma & G-+T- & 1.9 & $0.62-5.8$ \\
& AA+CC & 1.0 & - \\
& AA+T- & 0.48 & $0.089-2.6$ \\
Bladder cancer & G-+CC & 1.1 & $0.41-3.1$ \\
& G-+T- & 2.5 & $0.84-7.4$ \\
& AA+CC & 1.0 & - \\
Breast cancer & AA+T- & 1.7 & $0.12-23$ \\
& G-+CC & 3.0 & $0.64-14$ \\
& G-+T- & $\mathbf{6 . 5}$ & $1.3-33$ \\
& AA+CC & 1.0 & - \\
& G-+CC & $\mathbf{2 . 8}$ & $1.1-7.2$ \\
& AA+T- & 12 & $\mathbf{2 . 1 - 7 0}$ \\
& G-+T- & 4.6 & $1.7-13$ \\
\hline
\end{tabular}

a Statistically significant associations $(p \leq 0.05)$ are denoted in bold. The analyses were adjusted for age and sex.

b For rs 1563634, the reference category was changed to the variant allele in order to display cancer risk increment.

selected SNPs were in HWE in the breast cancer control group as well (data not shown). The results from the initial screening of all SNPs and their association with AML/ MDS, malignant melanoma, and bladder cancer, are shown in Additional file 1. Few statistically significant findings were obtained when the tumour types were analysed separately. The SNP rs296887 (RMI1) was significantly associated with increased cancer risks for AML/ MDS, as well as for malignant melanoma, but not with risk for bladder cancer. In TOP3A, rs12945597 was associated with increased risk for AML/MDS and malignant
Table 4: Association of polymorphisms in TOP3A and BLM and risk of cancer (all cancer cases and all controls combined). ${ }^{a}$

\begin{tabular}{llllll}
\hline SNP & Genotype & OR & $95 \% \mathrm{Cl}$ & FPRP 0.Ib & FPRP 0.0I \\
\hline rsI563634c & AA & 1.0 & - & - & \\
$(T O P 3 A)$ & AG & $\mathbf{1 . 7}$ & $\mathbf{1 . 1 - 2 . 6}$ & $\mathbf{0 . 4 8}$ & $\mathbf{0 . 9 2}$ \\
& GG & $\mathbf{1 . 8}$ & $\mathbf{1 . 1 - 2 . 8}$ & $\mathbf{0 . 2 9}$ & $\mathbf{0 . 8 4}$ \\
rs $\mid 2945597$ & GG & 1.0 & - & - & - \\
$(T O P 3 A)$ & AG & $\mathbf{1 . 5}$ & $\mathbf{1 . 1 - 1 . 9}$ & $\mathbf{0 . 0 1 4}$ & $\mathbf{0 . 1 3}$ \\
& AA & $\mathbf{1 . 6}$ & $\mathbf{1 . 0 - 2 . 5}$ & $\mathbf{0 . 3 6}$ & $\mathbf{0 . 8 9}$ \\
rs40I549 & AA & 1.0 & - & - & - \\
$(B L M)$ & AG & 1.2 & $0.89-1.5$ & - & - \\
& GG & 1.3 & $0.82-2.2$ & - & - \\
rs2532I05 & CC & 1.0 & - & - & - \\
$(B L M)$ & CT+TT & $\mathbf{1 . 8}$ & $\mathbf{1 . 5 - 2 . 5}$ & $\mathbf{0 . 0 2 9}$ & $\mathbf{0 . 2 7}$ \\
\end{tabular}

a Statistically significant associations $(p \leq 0.05)$ are denoted in bold. The analyses were adjusted for age and sex.

b FPRP is only calculated for significant $\mathrm{p}$-values.

c For rs 1563634, the reference category was changed to the variant allele in order to display cancer risk increment.

melanoma, and showed a non-significantly increased risk for bladder cancer. In BLM, rs401549 was associated with significantly increased risk for bladder cancer and a nonsignificantly increased risk for malignant melanoma. Rs2532105 (BLM) showed increased risk for malignant melanoma and bladder cancer, and a non-significant risk increment for AML/MDS. In AML/MDS, rs393974 (BLM) and rs6496724 (BLM) were also significantly associated with cancer risk.

For further analysis of breast cancer, rs12945597 in TOP3A, rs401549, and rs2532105 in BLM were selected, as well as rs1563634 in TOP3A, which showed similar non-significant protective effects in all three cancer forms for the variant homozygous carriers. For rs 1563634 , the reference category was in the subsequent analyses changed to the variant homozygotes in order to display cancer risk increment. The rs12945597 in TOP3A and rs2532105 in BLM (Table 2) was significantly associated with increased breast cancer risk. Dual-polymorphisms

Table 5: Gene-gene associations of polymorphisms in TOP3A and $B L M$ and risk of cancer (all cancer cases and all controls combined). ${ }^{a}$

\begin{tabular}{llll}
\hline Polymorphisms & Genotype & OR & $95 \% \mathrm{Cl}$ \\
\hline rs12945597+rs2532105 & GG+CC & 1.0 & - \\
& A-+CC & 1.6 & $\mathbf{I . 2 - 2 . 1}$ \\
& GG+T- & 2.0 & $1.3-3.1$ \\
rs1563634+rs2532105 & A-+T- & 2.7 & $1.8-4.3$ \\
& AA+CC & 1.0 & - \\
& G-+CC & 1.9 & $1.1-3.2$ \\
& AA+T- & 2.0 & $0.85-4$. \\
& G-+T- & 3.5 & $\mathbf{2 . 0 - 6 . 3}$
\end{tabular}

a Statistically significant associations $(p \leq 0.05)$ are denoted in bold. The analyses were adjusted for age and sex. 
analyses (in two different genes) were performed for all cancer forms for the three SNPs showing main genetic effects (Table 3). An allele-dosage effect was found for the combination rs12945597 (TOP3A) and rs2532105 (BLM) for AML/MDS, bladder and breast cancer, where carriers with two variant alleles displayed the highest risks (Table $3 \mathrm{~A})$.

Based on these results, we combined all cases $(\mathrm{N}=584)$ and controls $(\mathrm{N}=406)$, respectively and performed association analyses. The cases and controls showed a similar distribution in age (cases median age $=65$ years, controls $=64$ years), but differed for sex ( $63 \%$ women among cases and 54\% women among controls). For rs1563634, rs12945597, and rs2532105, a significantly increased risk for developing cancer was found (Table 4). The highest risk was found for the combination of rs1563634 in TOP3A and rs2532105 in BLM (OR = 3.5, 95\% CI 2.06.3; Table 5). We also performed a three-polymorphism combination analysis for TOP3A rs1563634 and rs12945597, and $B L M$ rs 2532105 and found an $O R=3.8$, 95\% CI 2.0-7.3, for carriers of three variant alleles.

The impact of age on the associations between genetic markers of the BLM-complex and cancer risk was evaluated. For the two polymorphisms in TOP3A a stronger effect was found among elderly individuals (rs1563634 GG carriers $\geq 65$ years OR $=2.295 \%$ CI $1.2-4.0,<65$ years $\mathrm{OR}=1.495 \%$ CI $0.73-2.7 ;$ rs 12945597 AA carriers $\geq 65$ years $\mathrm{OR}=2.395 \% \mathrm{CI} 1.2-4.4,<65$ years $\mathrm{OR}=1.195 \% \mathrm{CI}$ $0.58-2.0$ ). No such effect could be detected for the two variants analysed in BLM (data not shown).

We evaluated the significance of the findings for all cancer cases and controls combined by using FPRP analysis (Table 4). At high prior probability (set as 0.1 ) all statistically significant findings demonstrated a low probability for false positive results. However, at a lower prior probability (0.01), only the TOP3A rs12945597 (heterozygote) and BLM rs2532105 displayed a FPRP value $<0.5$.

The bioinformatics analyses revealed that TOP3A rs1563634 is situated in a CpG island about 700 base pairs upstream to the start codon in TOP3A. TOP3A rs12945597 is located approximately $5 \mathrm{Kbp}$ downstream the coding region. BLM rs401549 and rs2532105 are situated in intron 21 of the gene.

\section{Discussion}

The present study shows that individuals carrying genetic variants of the BLM-TOP3A-RMI1 complex have an increased risk of AML/MDS, malignant melanoma, bladder and breast cancer. The strongest genetic risk marker was found in BLM, i.e., the variant allele of rs2532105, which showed a statistically significantly increased risk for three out of four cancer forms analyzed. By considering two polymorphisms a stronger association was obtained, but there were no indications of a multiplicative interaction between genetic variants at different gene loci.

These data suggests that some polymorphisms in the BLM complex are general cancer susceptibility markers and that the homologous recombination system may be involved in neoplastic transformation of several cell types. Our finding is in line with the observation that individuals with Blooms syndrome carrying mutations in BLM, essential for the homologous recombination complex, show elevated risk for various cancer types. There are increasing amount of evidence that homologous recombination generates loss of heterozygosity in various cancer types e.g. acute myeloid leukemias, follicular lymphomas, breast cancer, bladder cancer, gastrointestinal stromal tumors and Barrett's oesophagus [15-20]. A recent study have also shown the importance of the BLM-TOP3A-RMI1 for the maintenance of the genome stability by faithful chromosome segregation and prevention of anaphase bridges[21], a cytogenetic aberration found in several types of neoplastic cells. In a recent investigation, we found a more pronounced effect among elderly individuals for the Ser455Asn polymorphism in RMI1 [7]. We found a similar pattern in this study for the two polymorphisms in TOP3A, possibly reflecting the finding that mitotic recombination increases with age [22] and, hypothetically, that protein variants involved in this process has a larger influence when the body burden of mitotic recombination increases.

The effect of the polymorphisms remains to be clarified. None of the three rs1563634, rs12945597, and rs2532105 result in non-synonymous exchanges or are in LD with non-synonymous SNPs (data not shown). However, rs1563634 is positioned in a CpG island upstream to the TOP3A gene. The SNP does not in itself introduce or remove an extra $\mathrm{CpG}$, but $\mathrm{CpG}$ regions tend to be associated with gene promoter regions and hence the polymorphism may affect transcriptional activity [23].

There are several limitations with the study. One problem is that smaller case-control studies may lead to spurious association and it is important to stress that our findings need to be confirmed in other case-control studies. For bladder cancer, the drop out in genotype data/assay was fairly high and these data should thus be cautiously interpreted. The characteristics of the control groups differed; they were selected in different ways during different time frames, showed varying degree of participation, and varied in sex and age distribution. However, allelic frequencies in the different control groups were similar, indicating that the observed frequencies are good estimates of the true frequency in this region of Sweden. On 
the other hand, there were different allelic distributions for the SNPs in the different cancer forms. Different repair pathways are important for different cancer forms, but based on our results on each cancer form, homologous recombination may be important in several cancer types. However, the genetic influence is not expected to be exactly the same for the different cancers and therefore, the allelic frequencies may differ. Since the separate analysis for each cancer points at influence of the BLM system, it was considered acceptable to combine all cases and controls, despite the fact that the cancer forms in this study are very different in etiology, and genetic heterogeneity is present in different tumour forms. When the cases from all cancer forms and the different control groups were combined in one analysis, the case and control groups differed somewhat in sex, but were very similar in age distribution. Still, it should be noted that apart from factors as age and sex, we have not evaluated cancer-specific risk factors, which could influence the associations between SNPs in the BLM complex and cancer risk.

We conducted a false-positive report probability (FPRP) analyses in order to assess the risk of false positives. The prior probabilities were considered relatively high $(0.1)$ due to the impact of mutations in $B L M$ for cancer risk in Bloom syndrome patients and the functional relevance of the TOP3A for the BLM complex. However, since there was little evidence for functional effect for the SNPs analysed, based on bioinformatics analysis, the prior probability of 0.01 was also taken into consideration. With this cut-off, only the TOP3A rs12945597 and BLM rs2532105 remained as significant findings. Thus, the other observed associations in this study have to be validated in a larger cohort.

There are very few other studies of polymorphisms of the BLM-complex and cancer risk. As mentioned, we have previously studied the Ser455Asn polymorphism in RMI1 and found an association between increased risk of AML/ MDS and malignant melanoma for variant carriers. In this study, we analysed the SNP rs296887, which is linked to RMI1 Ser455Asn and found a similar but weaker effect for AML/MDS and malignant melanoma but no effect in bladder cancer. Other studies have analyzed BLM Thr298Met and small cell lung carcinoma risk [24] and BLM Pro868Leu and familial breast cancer [25], but none of these polymorphisms showed any association with cancer risk. However, there are several studies on other genes that are required for homologous recombination repair, i.e. RAD51, XRCC2 and XRCC3. The RAD51-135 (G/C) variant allele has been associated with increased risk of AML and this relation was most pronounced for AML associated with a previous history of treatment with chemo- or radiotherapy [26-29]. The results for the XRCC3 Thr241Met variant have so far been not been con- clusive: variant carriers was found to have increased risk of bladder and breast cancer and malignant melanoma [3032 ], whereas in a previous study of ours no association with this marker and bladder cancer was demonstrated [8]. In one meta-analysis, there was no significant associations between XRCC3 Thr241Met and cancer of the bladder, breast, lung or skin [33], but in another meta-analysis the Met/Met genotype showed a small cancer risk with the strongest effect found for breast cancer [34]. Also for the $X R C C 2$ gene the results have been contradictory, the variant allele of Arg188His has been associated with increased cancer risk for breast and pharyngeal cancer and smokingrelated pancreatic cancer [35-37], whereas for epithelial ovarian cancer there was no effect or a reduced risk[38,39].

\section{Conclusion}

Our data indicate that variants of the BLM-TOP3A-RMI1 recombination complex, has an impact on cancer risk. Since the SNPs are common among our subjects with AML/MDS, malignant melanoma, bladder and breast cancer, even the moderate increase in risk observed in this study may be associated with a considerable impact. However, the results need to be confirmed in subsequent studies.

\section{Abbreviations}

CI: confidence interval; FPRP: false-positive report probability; HWE: Hardy Weinberg equilibrium; Kbp: kilobasepairs; OR: odds ratio; SNP: single nucleotide polymorphism.

\section{Competing interests}

$\mathrm{KB}, \mathrm{HO}$ and $\mathrm{MH}$ are currently applying for a patent relating to the content of the manuscript.

\section{Authors' contributions}

EH performed the genotyping; KE carried out the analysis on bioinformatics; $\mathrm{EH}$ and JB performed the statistical analysis; $\mathrm{CI}, \mathrm{MA}$, and $\mathrm{HO}$ have designed the case-control studies for the different cancer forms and collected the samples; KB drafted the manuscript and together with $\mathrm{MH}$ and $\mathrm{HO}$ conceived the study, and participated in its design and coordination. All authors contributed to the writing and have approved the manuscript. 


\section{Additional material}

\section{Additional file 1}

Supplementary tables I-III. Table I. Influence of all polymorphisms studied in RMI1, TOP3A, and BLM on risk for AML/MDS (acute myeloid leukemia/myelodysplastic syndromes). Table II. Influence of all polymorphisms studied RMI1, TOP3A, and BLM on risk for malignant melanoma. Table III. Influence of all polymorphisms studied in RMI1, TOP $3 A$, and BLM on risk for bladder cancer.

Click here for file

[http://www.biomedcentral.com/content/supplementary/14712407-9-140-S1.doc]

\section{Acknowledgements}

The authors would like to thank Karin Paulsson for technical assistance with the genotyping. Grant support: Swedish Council for Working Life and Social Research, Swedish Cancer Society, The Swedish Research Council, The Nilsson Cancer Foundation, The Crafoord foundation, Cancer and Allergy foundation, The Lund University hospital, Erik-Philip Sörensons foundation.

\section{References}

I. German J: Bloom syndrome: a mendelian prototype of somatic mutational disease. Medicine (Baltimore) 1993, 72(6):393-406.

2. Wu L, Hickson ID: The Bloom's syndrome helicase suppresses crossing over during homologous recombination. Nature 2003, 426(6968):870-874.

3. Meetei AR, Sechi S, Wallisch M, Yang D, Young MK, Joenje H, Hoatlin ME, Wang W: A multiprotein nuclear complex connects Fanconi anemia and Bloom syndrome. Mol Cell Biol 2003, 23(10):3417-3426.

4. Yin J, Sobeck A, Xu C, Meetei AR, Hoatlin M, Li L, Wang W: BLAP75, an essential component of Bloom's syndrome protein complexes that maintain genome integrity. Embo J 2005, 24(7): |465-|476.

5. Mankouri HW, Hickson ID: The RecQ helicase-topoisomerase III-Rmil complex: a DNA structure-specific 'dissolvasome'? Trends Biochem Sci 2007, 32(I 2):538-546.

6. Ralf C, Hickson ID, Wu L: The Bloom's syndrome helicase can promote the regression of a model replication fork. J Biol Chem 2006, 28 I(32):22839-22846.

7. Broberg K, Höglund M, Gustafsson C, Björk J, Ingvar C, Albin M, Olsson $\mathrm{H}$ : Genetic variant of the human homologous recombination-associated gene RMII (S455N) impacts the risk of AML/ MDS and malignant melanoma. Cancer Lett 2007, 258(I):38-44.

8. Broberg K, Björk J, Paulsson K, Höglund M, Albin M: Constitutional short telomeres are strong genetic susceptibility markers for bladder cancer. Carcinogenesis 2005, 26(7): I 263-I27I.

9. Barrett JC, Fry B, Maller J, MJ D: Haploview: analysis and visualization of LD and haplotype maps. Bioinformatics 2005, 2 I(2):263-265.

10. Wacholder S, Chanock S, Garcia-Closas M, El Ghormli L, Rothman N: Assessing the probability that a positive report is false: an approach for molecular epidemiology studies. I Natl Cancer Inst 2004, 96(6):434-442.

I I. Engel LS, Taioli E, Pfeiffer R, Garcia-Closas M, Marcus PM, Lan Q, Boffetta $P$, Vineis $P$, Autrup $H$, Bell DA, et al: Pooled analysis and meta-analysis of glutathione S-transferase $M I$ and bladder cancer: a HuGE review. Am J Epidemiol 2002, I 56(2):95-I09.

12. Marcus PM, Vineis P, Rothman N: NAT2 slow acetylation and bladder cancer risk: a meta-analysis of 22 case-control studies conducted in the general population. Pharmacogenetics 2000, I0(2): II5-122.

13. Conde L, Vaquerizas JM, Dopazo H, Arbiza L, Reumers J, Rousseau F, Schymkowitz J, Dopazo J: PupaSuite: finding functional single nucleotide polymorphisms for large-scale genotyping purposes. Nucleic Acids Res 2006:W621-625.

14. Reumers J, Conde L, Medina I, Maurer-Stroh S, Durme JV, Dopazo J, Rousseau F, Schymkowitz J: Joint annotation of coding and noncoding single nucleotide polymorphisms and mutations in the SNPeffect and PupaSuite databases. Nucleic Acids Res 2008:D825-9.

15. Natrajan R, Louhelainen J, Williams S, Laye J, Knowles MA: High-resolution deletion mapping of I5qI3.2-q2 I. I in transitional cell carcinoma of the bladder. Cancer Res 2003, 63(22):7657-7662.

16. Cleton-Jansen AM, Buerger H, Haar N, Philippo K, Vijver MJ van de, Boecker W, Smit VT, Cornelisse C): Different mechanisms of chromosome 16 loss of heterozygosity in well-versus poorly differentiated ductal breast cancer. Genes Chromosomes Cancer 2004, 4 I(2): 109- I I6.

17. Lai LA, Paulson TG, Li X, Sanchez CA, Maley C, Odze RD, Reid BJ, Rabinovitch PS: Increasing genomic instability during premalignant neoplastic progression revealed through high resolution array-CGH. Genes Chromosomes Cancer 2007, 46(6):532-542.

18. Stewart DR, Corless CL, Rubin BP, Heinrich MC, Messiaen LM, Kessler LJ, Zhang PJ, Brooks DG: Mitotic recombination as evidence of alternative pathogenesis of gastrointestinal stromal tumours in neurofibromatosis type I. J Med Genet 2007, 44(I):e6I.

19. Fitzgibbon J, Smith LL, Raghavan M, Smith ML, Debernardi S, Skoulakis S, Lillington D, Lister TA, Young BD: Association between acquired uniparental disomy and homozygous gene mutation in acute myeloid leukemias. Cancer Res 2005, 65(20):9152-9154.

20. Fitzgibbon J, Iqbal S, Davies A, O'Shea D, Carlotti E, Chaplin T, Matthews J, Raghavan M, Norton A, Lister TA, et al.: Genome-wide detection of recurring sites of uniparental disomy in follicular and transformed follicular lymphoma. Leukemia 2007, 2I(7): I $514-1520$.

21. Chan KL, North PS, Hickson ID: BLM is required for faithful chromosome segregation and its localization defines a class of ultrafine anaphase bridges. Embo J 2007, 26( I 4):3397-3409.

22. Grist SA, McCarron M, Kutlaca A, Turner DR, Morley AA: In vivo human somatic mutation: frequency and spectrum with age. Mutat Res 1992, 266(2): 189-196.

23. Fazzari MJ, Greally JM: Epigenomics: beyond CpG islands. Nat Rev Genet 2004, 5(6):446-455.

24. Kohno T, Sakiyama T, Kunitoh H, Goto K, Nishiwaki Y, Saito D, Hirose H, Eguchi T, Yanagitani N, Saito R, et al.: Association of polymorphisms in the MTHI gene with small cell lung carcinoma risk. Carcinogenesis 2006, 27( I 2):2448-2454.

25. Wirtenberger M, Frank B, Hemminki K, Klaes R, Schmutzler RK, Wappenschmidt B, Meindl A, Kiechle M, Arnold N, Weber BH, et al: Interaction of Werner and Bloom syndrome genes with p53 in familial breast cancer. Carcinogenesis 2006, 27(8): |655-|660.

26. Seedhouse C, Faulkner R, Ashraf N, Das-Gupta E, Russell N: Polymorphisms in genes involved in homologous recombination repair interact to increase the risk of developing acute myeloid leukemia. Clin Cancer Res 2004, I 0(8):2675-2680.

27. Jawad M, Seedhouse CH, Russell N, Plumb M: Polymorphisms in human homeobox HLXI and DNA repair RAD5 I genes increase the risk of therapy-related acute myeloid leukemia. Blood 2006, 108(12):3916-3918.

28. Bhatla D, Gerbing RB, Alonzo TA, Mehta PA, Deal K, Elliott J, Meshinchi S, Geiger H, Perentesis JP, Lange BJ, et al.: DNA repair polymorphisms and outcome of chemotherapy for acute myelogenous leukemia: a report from the Children's Oncology Group. Leukemia 2008, 22(2):265-72.

29. Voso MT, Fabiani E, D'Alo F, Guidi F, Di Ruscio A, Sica S, Pagano L, Greco M, Hohaus S, Leone G: Increased risk of acute myeloid leukaemia due to polymorphisms in detoxification and DNA repair enzymes. Ann Oncol 2007, I 8(9): I523-I528.

30. Winsey SL, Haldar NA, Marsh HP, Bunce M, Marshall SE, Harris AL, Wojnarowska $\mathrm{F}$, Welsh $\mathrm{KI}$ : A variant within the DNA repair gene XRCC3 is associated with the development of melanoma skin cancer. Cancer Res 2000, 60(20):56I2-56 I6.

31. Figueroa JD, Malats N, Rothman N, Real FX, Silverman D, Kogevinas M, Chanock S, Yeager M, Welch R, Dosemeci M, et al.: Evaluation of genetic variation in the double-strand break repair pathway and bladder cancer risk. Carcinogenesis 2007, 28(8): | 788- | 793. 
32. Sangrajrang $S$, Schmezer $P$, Burkholder I, Boffetta $P$, Brennan $P$, WoeIfelschneider A, Bartsch H, Wiangnon S, Cheisilpa A, Popanda O: The XRCC3 Thr24IMet polymorphism and breast cancer risk: a case-control study in a Thai population. Biomarkers 2007, I 2(5):523-532.

33. Manuguerra M, Saletta F, Karagas MR, Berwick $M$, Veglia F, Vineis $P$, Matullo G: XRCC3 and XPD/ERCC2 single nucleotide polymorphisms and the risk of cancer: a HuGE review. Am J Epidemiol 2006, 164(4):297-302.

34. Han S, Zhang HT, Wang Z, Xie Y, Tang R, Mao Y, Li Y: DNA repair gene XRCC3 polymorphisms and cancer risk: a meta-analysis of 48 case-control studies. Eur J Hum Genet 2006, I 4( I0): | | 36- | | 44 .

35. Benhamou S, Tuimala J, Bouchardy C, Dayer P, Sarasin A, Hirvonen $A$ : DNA repair gene $X R C C 2$ and $X R C C 3$ polymorphisms and susceptibility to cancers of the upper aerodigestive tract. Int J Cancer 2004, I I 2(5):901-904.

36. Danoy P, Sonoda E, Lathrop M, Takeda S, Matsuda F: A naturally occurring genetic variant of human XRCC2 $(R \mid 88 \mathrm{H})$ confers increased resistance to cisplatin-induced DNA damage. Biochem Biophys Res Commun 2007, 352(3):763-768.

37. Jiao L, Hassan MM, Bondy ML, Wolff RA, Evans DB, Abbruzzese JL, Li D: XRCC2 and XRCC3 Gene Polymorphismand Risk of Pancreatic Cancer. Am J Gastroenterol 2008, 103(2):360-7.

38. Auranen A, Song $H$, Waterfall $C$, Dicioccio RA, Kuschel B, Kjaer SK, Hogdall E, Hogdall C, Stratton J, Whittemore AS, et al:: Polymorphisms in DNA repair genes and epithelial ovarian cancer risk. Int J Cancer 2005, I I 7(4):6II I-6I8.

39. Beesley J, Jordan SJ, Spurdle AB, Song H, Ramus SJ, Kjaer SK, Hogdall E, Dicioccio RA, McGuire V, Whittemore AS, et al.: Association between single-nucleotide polymorphisms in hormone metabolism and DNA repair genes and epithelial ovarian cancer: results from two Australian studies and an additional validation set. Cancer Epidemiol Biomarkers Prev 2007, I 6( I 2):2557-2565.

\section{Pre-publication history}

The pre-publication history for this paper can be accessed here:

http://www.biomedcentral.com/1471-2407/9/140/pre pub

Publish with Bio Med Central and every scientist can read your work free of charge

"BioMed Central will be the most significant development for disseminating the results of biomedical research in our lifetime. "

Sir Paul Nurse, Cancer Research UK

Your research papers will be:

- available free of charge to the entire biomedical community

- peer reviewed and published immediately upon acceptance

- cited in PubMed and archived on PubMed Central

- yours - you keep the copyright
BioMedcentral 